\title{
Branched Polymeric Media: Boron-Chelating Resins from Hyperbranched Polyethylenimine
}

Himanshu Mishra, ${ }^{\dagger}$ Changjun Yu, ${ }^{\ddagger}, \|$ Dennis P. Chen, ${ }^{\S}$ William A. Goddard, III, ${ }^{\dagger, \S}$ Nathan F. Dalleska, Michael R. Hoffmann, $\|$ and Mamadou S. Diallo*,,$\|$

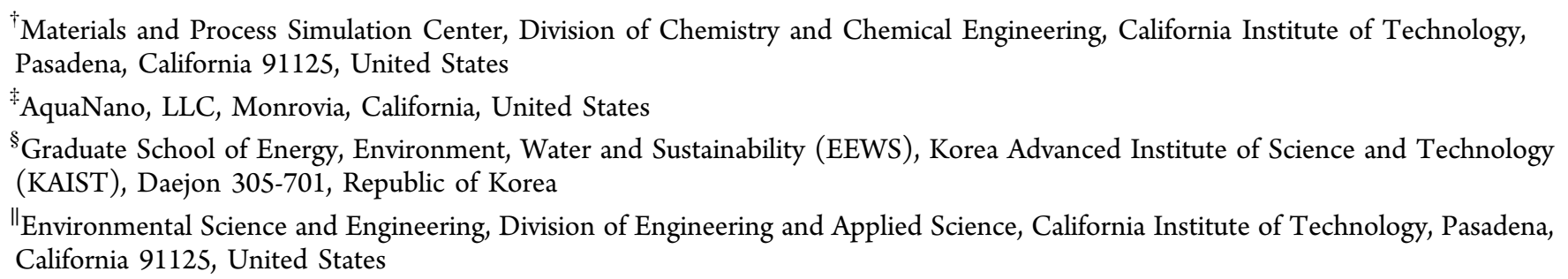

\section{Supporting Information}

ABSTRACT: Extraction of boron from aqueous solutions using selective resins is important in a variety of applications including desalination, ultrapure water production, and nuclear power generation. Today's commercial boron-selective resins are exclusively prepared by functionalization of styrene-divinylbenzene (STY-DVB) beads with $N$-methylglucamine to produce resins with boron-chelating groups. However, such boron-selective resins have a limited binding capacity with a maximum free base content of $0.7 \mathrm{eq} / \mathrm{L}$, which corresponds to a sorption capacity of $1.16 \pm 0.03 \mathrm{mMol} / \mathrm{g}$ in aqueous solutions with equilibrium boron concentration of $\sim 70 \mathrm{mM}$. In this article, we describe the synthesis and characterization of a new resin that can selectively extract boron from aqueous solutions. We show that branched polyethylenimine (PEI) beads obtained from an inverse suspension process can be reacted with glucono1,5-D-lactone to afford a resin consisting of spherical beads with high density of boron-chelating groups. This resin has a sorption capacity of $1.93 \pm 0.04 \mathrm{mMol} / \mathrm{g}$ in aqueous solution with equilibrium boron concentration of $\sim 70 \mathrm{mM}$, which is $66 \%$ percent larger than that of standard commercial STY-DVB resins. Our new boron-selective resin also shows excellent regeneration efficiency using a standard acid wash with a $1.0 \mathrm{M} \mathrm{HCl}$ solution followed by neutralization with a $0.1 \mathrm{M} \mathrm{NaOH}$ solution.

\section{INTRODUCTION}

Extraction of boron from aqueous solutions is important in a variety of applications including (i) desalination, (ii) ultrapure water treatment, (iii) the production of high purity magnesium oxide from brines, and (iv) nuclear power generation. ${ }^{1-4}$ Boron plant growth and damages crops (e.g., citrus and corn) when desalinated water containing more than $0.3 \mathrm{mg} / \mathrm{L}$ of boron is used in irrigation. ${ }^{2}$ In semiconductor manufacturing, boron is used as a p-type dopant to silicon. ${ }^{6}$ To control the level of boron in a silicon chip, ultrapure water with boron concentrations less than $1 \mathrm{ppb}(\mu \mathrm{g} / \mathrm{L})$ is required. In the production of high-purity magnesium oxides by pyrohydrolysis of magnesium chloride $\left(\mathrm{MgCl}_{2 .}\right)$ brine, excess boron $(>10 \mathrm{mg} /$ products. ${ }^{3}$ In nuclear power generation, ${ }^{10} \mathrm{~B}$-enriched mixtures of boric acid with lithium hydroxide provide inexpensive yet efficient neutron-absorbing media in the primary coolant water of pressurized water reactors. The availability of an efficient and highly selective boric acid recovery system is the key bottleneck is an essential nutrient for plants. ${ }^{5}$ However, it adversely affects $\mathrm{L}$ ) in the brine causes embrittlment of the final metal oxide

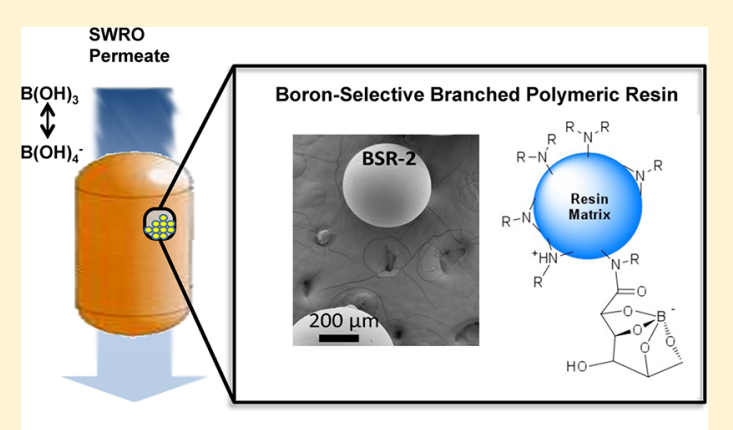

Boron-Free

Desalinated

Water for the wide-scale implementation of these neutron-absorbing media. $^{4,7}$

Sorption with selective and regenerable resins has emerged as an efficient and cost-effective process for extracting boron from aqueous solutions. ${ }^{2}$ The predominant boron species in aqueous solutions, $\mathrm{H}_{3} \mathrm{BO}_{3}$ versus $\mathrm{B}(\mathrm{OH})_{4}{ }^{-}$, is determined by the $\mathrm{pH}$ of the solution $\left[\mathrm{H}_{3} \mathrm{BO}_{3}(\mathrm{aq}), \mathrm{p} K_{\mathrm{a}}=9.24\right]$. It is well-known that boron/borate can selectively complex with organic moieties containing two or more vicinal hydroxyl groups (e.g., diols). ${ }^{8}$ For example, host functionalization with diol-bearing compounds has been carried out on a variety of polymeric matrices and hybrid organic-inorganic mesoporous materials to synthesize boron-selective ligands and sorbents. ${ }^{7,9-11}$ Today's commercial boron-chelating resins are exclusively prepared by functionalization of cross-linked styrene-divinylbenzene (STY-

Received: April 17, 2012

Revised: July 3, 2012

Accepted: July 24, 2012

Published: July 24, 2012 


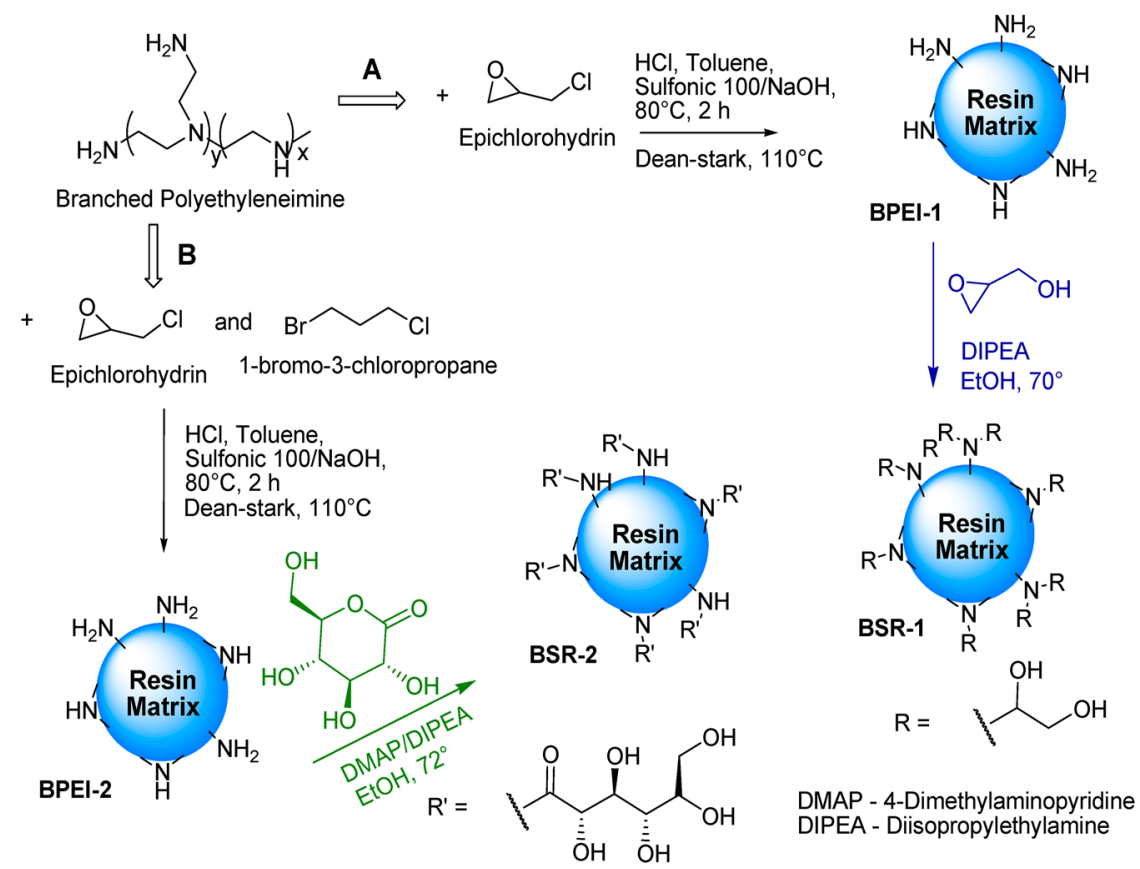

Figure 1. Synthesis and functionalization of PEI resins with boron-chelating groups. The Supporting Information (SI) provides a detailed description of the resin synthesis procedures.

DVB) beads with diol-bearing compounds such as $\mathrm{N}$ methylglucamine. However, commercial STY-DVB resins with $\mathrm{N}$-methylglucamine groups (e.g., the Amberlite IRA-743 resin) have a limited capacity with a maximum free base of $0.7 \mathrm{eq} / \mathrm{L}$, which corresponds to a sorption capacity of $1.09 \mathrm{mMol} / \mathrm{g}$ in aqueous solutions with equilibrium boron concentration of $\sim 100 \mathrm{mM}^{12}$ In this article, we describe the synthesis and characterization of a new family of resins that can selectively extract boron from aqueous solutions. We show that crosslinked branched polyethylenimine (PEI) beads obtained from an inverse suspension process can be reacted with glucono-1,5D-lactone to afford a resin consisting of spherical beads with high density of boron-chelating groups. This regenerable resin has a sorption capacity of $1.93 \pm 0.04 \mathrm{mMol} / \mathrm{g}$ in aqueous solutions with equilibrium boron concentration of $\sim 70 \mathrm{mM}$, which is $66 \%$ percent larger than that of standard commercial STY-DVB resins. The overall results of our study suggest that cross-linked branched PEI beads provide versatile and promising building blocks for the preparation of regenerable boron-chelating resins with high binding capacity.

\section{EXPERIMENTAL METHODS AND PROCEDURES}

Chemicals and Materials. Reagent grade chemicals were used to synthesize all the base PEI beads and boron-selective PEI resins described in this study. Reagent grade (>98 wt \%) anhydrous potassium chloride $(\mathrm{KCl})$, sodium chloride $(\mathrm{NaCl})$, and sodium sulfate $\left(\mathrm{Na}_{2} \mathrm{SO}_{4}\right)$, and ACS grade (99.5\%) boric acid were purchased from Alfa Aesar. Concentrated hydrochloric acid (12 M) was purchased from EMD. The precursor polyethylenimine macromolecules (PEI) (SP-018 (molecular weight $\left.M_{\mathrm{n}}=1800\right)$ and SP-200 $\left.\left(M_{\mathrm{n}}=10,000\right)\right)$ were purchased from Nippon Shokubai Co., Ltd. Sulfonic 100 (branched dodecyl benzene sulfonic acid, 97\%) was purchased from the Stepan Company. Reagent grade $(\geq 99.0 \%)$ D-glucono-1,5lactone, 1-bromo-3-chloropropane (BCP), diisopropylethylamine (DIPEA), and epichlorohydrin $(\mathrm{ECH})$ were purchased from Sigma-Aldrich. Methanol, ethanol, toluene, sodium bicarbonate $\left(\mathrm{NaHCO}_{3}\right)$, calcium chloride dihydrate $\left(\mathrm{CaCl}_{2} \cdot 2 \mathrm{H}_{2} \mathrm{O}\right)$, magnesium chloride hexahydrate $\left(\mathrm{MgCl}_{2} \cdot 6 \mathrm{H}_{2} \mathrm{O}\right)$, and sodium hydroxide $(\mathrm{NaOH})$ were purchased from Mallinckrodt Chemicals. Deionized (DI) water was obtained from a Milli-Q filtration unit (minimum resistivity $18 \mathrm{M} \Omega \mathrm{cm}^{-1}$ ). All chemicals were used as received. The commercial STY-DVB resin Amberlite IRA-743, which was specifically designed to remove boric acid and borate from aqueous solutions, was purchased from the Dow Chemical Company (Midland, MI, USA).

Resin Synthesis. All base PEI beads (BPEI-1 and BPEI-2) were synthesized using an inverse suspension of water-intoluene stabilized by a surfactant (Figure 1). The base PEI beads were functionalized, respectively, with 2-oxiranylmethanol and glucono-1,5-D-lactone to produce two resins (BSR-1 and BSR-2) with boron-chelating groups (Figure 1). The Supporting Information (SI) provides a detailed description of the resin synthesis procedures.

Resin Characterization. The boron-selective PEI resins (BSR-1 and BSR-2) were characterized using a broad range of analytical techniques/assays including (i) FT-IR spectroscopy, (ii) scanning electron microscopy (SEM), (iii) particle size distribution (PSD) analysis, and (iv) measurements of water and amine contents. The FT-IR spectra were acquired using a Bruker VERTEX 70/70v FT-IR spectrometer with potassium bromide $(\mathrm{KBr})$ pellets and OPUS software for data processing. All the reported IR spectra represent averages of more than 100 consecutive scans. The SEM images were acquired using a Zeiss 1500VP field-emission scanning electron microscope. Prior to imaging, each resin sample was coated with a thin and conducting graphite film. The average diameter of the BSR-1 beads was determined using the ImageJ software. ${ }^{13}$ The mean diameter of the BSR-2 beads was measured using a Malvern Hydro 2000S particle size analyzer. The SEM images (Figure $1 S$ ) and particle size distribution (Figure $2 S$ ) are provided in the SI. 
The water content of each resin was determined by drying a $2 \mathrm{~g}$ sample of media in a desiccator at ambient temperature under vacuum and recording its weight until it remained constant. The free base capacity (amine content) of each resin was determined by performing a Mohr titration as described in ASTM 2187 sections $100-109 .^{14}$ In a typical titration experiment, $4 \mathrm{~g}$ of resin was mixed with $10 \mathrm{~mL}$ of deionized water. The resin slurry was packed in a graduated cylinder and allowed to equilibrate for $1 \mathrm{~h}$. The bed volume (BV) of the resin was then measured. Subsequently, the resin slurry was packed in a fritted glass column and filled with $1 \mathrm{~L}$ of a $1.2 \mathrm{M}$ $\mathrm{HCl}$ solution. The acid was passed through the sample at the rate of $20-25 \mathrm{~mL} / \mathrm{min}$, keeping the samples submerged in acid at all times. Following this, the liquid was drained to the level of the samples and the effluent liquid was discarded. The column was then washed with $600-750 \mathrm{~mL}$ of ethanol until a $10-\mathrm{mL}$ portion of the effluent mixed with $10 \mathrm{~mL}$ of water achieved a constant $\mathrm{pH}>4.0$. The chloride ions bound to the protonated amine groups of the resins were then eluted out with a $1 \mathrm{~L}$ of 2.0 wt \% solution of sodium nitrate $\left(\mathrm{NaNO}_{3}\right)$. Following this, the concentration of chloride in the effluent was measured by titrating $100 \mathrm{~mL}$ of the effluent solution with a solution of silver nitrate $\left(\mathrm{AgNO}_{3}\right)$. The total amine content (TAC) $(\mathrm{meq} / \mathrm{mL})$ was expressed as

$$
\mathrm{TAC}=V \times N \times \mathrm{DR} / \mathrm{BV}
$$

where $V$ and $N$ are, respectively, the volume $(\mathrm{mL})$ and normality (meq/mL) of the $\mathrm{AgNO}_{3}$ solution, $\mathrm{BV}(\mathrm{mL})$ is the volume of the swollen resin, and DR is the dilution ratio, which is equal to 10 in this case.

Boron Sorption onto Pristine Resins. To evaluate the performance of our new boron-selective resins, we carried out batch studies to measure their sorption capacity in deionized (DI) water and model electrolyte solutions. Batch sorption studies were carried out to measure the boron sorption capacity of the pristine BSR-1 and BSR-2 resins in DI water, $0.1 \mathrm{M} \mathrm{NaCl}$ solution, and a model permeate from a seawater reverse osmosis (SWRO) plant (Table 1S of the SI). To benchmark the performance of the BSR-1 and BSR-2 resins, we also measured the boron sorption capacity of a commercial STYDVB resin with boron-chelating groups (IRA-743) in DI water. Boron sorption onto each resin was measured by mixing known amounts of dry resin with aqueous solutions (at neutral $\mathrm{pH}$ ) containing varying concentrations of boron. Following equilibration of the vials for $24 \mathrm{~h}$, the amount of boron sorbed onto each resin $\left(Q_{\text {sorbed }}\right)$ (millimoles of boron per $g$ of resin) was determined using the following equation:

$$
Q_{\text {sorbed }}=\left(C_{\mathrm{bi}}-C_{\mathrm{bf}}\right) / m
$$

where $C_{\mathrm{bi}}$ and $C_{\mathrm{bf}}$ are, respectively, the initial and final concentrations of boron $(\mathrm{mM})$ in solution measured by titration and $m$ is the dry-mass of resin $(\mathrm{g})$ per volume of solution (L). In a typical titration experiment, $10 \mathrm{~mL}$ of a $0.5 \mathrm{M}$ mannitol solution was first added to an aliquot of $1.0 \mathrm{~mL}$ of supernatant solution (analyte) from each equilibrated sorption vial. Excess mannitol ensured complete binding of the dissolved boron and release of protons $\left(\mathrm{H}_{3} \mathrm{O}^{+}\right) .{ }^{8}$ Subsequently, each analyte was titrated against a $0.05 \mathrm{M} \mathrm{NaOH}$ solution (using phenolphthalein as indicator) until it became and remained pink for more than $30 \mathrm{~s}$. The concentration of boron in the supernatant solution $\left(C_{\mathrm{bf}}\right)$ after equilibration was calculated using the following equation:

$$
C_{\mathrm{bf}}=C_{\mathrm{NaOH}} \times\left(V_{\mathrm{NaOH}} / V_{\text {analyte }}\right)
$$

where $V_{\mathrm{NaOH}}$ and $C_{\mathrm{NaOH}}$ are, respectively, the volume $(\mathrm{mL})$ and concentration $(\mathrm{mM})$ of the $\mathrm{NaOH}$ solution, and $V_{\text {analyte }}$ is the volume of analyte $(\mathrm{mL})$. Figure $3 \mathrm{~S}$ shows that the target and measured boron concentrations in a series of samples in DI water are within $0.5-3 \%$ thereby confirming the accuracy/ precision of the titration method in aqueous solutions with boron concentration $>2 \mathrm{mM}^{8}$

Boron Sorption onto Regenerated Resins. We also carried out batch studies to measure the boron sorption capacity of the BSR-1 and BSR-2 resins following one regeneration cycle. In a typical experiment, $1 \mathrm{~g}$ of resin (dryweight equivalent) was packed in a fritted glass column and eluted with a $50 \mathrm{mM}$ boric acid solution until the effluent concentration was equal to the feed concentration. The resin was regenerated by elution with a $1.0 \mathrm{M} \mathrm{HCl}$ solution followed by neutralization with $0.1 \mathrm{M} \mathrm{NaOH}$ solution. Similar regeneration conditions were employed in previous studies of boron-selective resins., ${ }^{9,12}$ Each regenerated resin was subsequently washed with DI water until the $\mathrm{pH}$ of the rinsewater remained constant $(\mathrm{pH} \sim 6.0)$. The neutralized resins were collected by filtration over a Büchner funnel. Batch sorption studies were subsequently carried out to measure the boron sorption capacity of the regenerated BSRs in DI water using the procedures described above.

\section{RESULTS AND DISCUSSION}

Resin Synthesis and Characterization. Boron-selective resins (BSRs) such as the commercial Amberlite IRA-743 resin are prepared by functionalization of cross-linked STY-DVB beads using a two-step process. ${ }^{15}$ In the first step, chloromethyl groups are attached to the STY-DVB resins via a Friedel-Crafts reaction involving the aromatic rings of the resin and an alkyl halide such as chloromethoxymethane in the presence of a Lewis acid catalyst. In the second step, the chloromethyl groups are reacted with $\mathrm{N}$-methylglucamine to produce boronchelating resins with vicinal diol groups. While the amination of chloromethylated STY-DVB beads is a facile reaction, which takes place in high yield, extensive side-reactions including the secondary cross-linking of the aromatic rings of STY-DVB beads via "methylene bridging" occur during chlomethylation. ${ }^{15,16}$ This reduces the number of functional sites available for amination and, as a result, STY-DVB resins with $\mathrm{N}$ methylglucamine groups such as the Amberlite IRA-743 resin have a limited capacity with a maximum free base of $0.7 \mathrm{eq} / \mathrm{L}$. In our efforts to develop BSRs with higher binding capacity than those of commercial STY-DVB resins, we selected branched polyethylenimine (PEI) as precursor both for its high content of reactive primary/secondary amine groups and availability from commercial sources. ${ }^{7,17,18}$ The new BSRs were prepared using a two-step process as illustrated in the reaction schemes shown in Figure 1. During the first step, two branched PEI macromolecules (with molar mass $\left(M_{n}\right)$ of 1800 and 10 $000 \mathrm{Da})$ were, respectively, cross-linked with epichlorohydrin and a mixture of epichlorohydrin (ECH) and 1-bromo-3chloropropane (DCP) to afford spherical beads using the inverse suspension process described by Chang et al. ${ }^{19}$ In the second step, the PEI beads (prepared using the PEI precursors with $M_{\mathrm{n}}=1800$ and $\left.10000 \mathrm{Da}\right)$ were functionalized, respectively, with 2-oxiranylmethanol and glucono-1,5-Dlactone to prepare two resins (BSR-1 and BSR-2) with boron-chelating groups. The SI provides all detailed descrip- 
tions of the procedures used to synthesize the BSR-1 and BSR2 resins. These new resins were characterized using a broad range of analytical techniques/assays including (i) measurements of water and amine contents, (ii) FT-IR spectroscopy, (iii) SEM imaging, and (iv) particle size distribution analysis.

Table 1 lists the total amine contents (TAC) of the BSR-1 and BSR-2 resins along with those of their precursor PEI beads

Table 1. Water and Total Amine Contents of BoronSelective and Base PEI Resins Evaluated in This Study

\begin{tabular}{|c|c|c|c|c|}
\hline resin & matrix & functional group & $\begin{array}{c}\text { water } \\
\text { content } \\
(\%)\end{array}$ & $\begin{array}{c}\text { total amine } \\
\text { content } \\
(\mathrm{mMol} / \mathrm{g})\end{array}$ \\
\hline BSR-1 & $\begin{array}{l}\text { cross- } \\
\text { linked } \\
\text { PEI }\end{array}$ & cis-diol & 37 & 8.02 \\
\hline BSR-2 & $\begin{array}{c}\text { cross- } \\
\text { linked } \\
\text { PEI }\end{array}$ & pentahydroxyhexanamide & 43 & 7.21 \\
\hline BPEI-1 & $\begin{array}{l}\text { cross- } \\
\text { linked } \\
\text { PEI }^{a}\end{array}$ & amines & 68 & 9.0 \\
\hline BPEI-2 & $\begin{array}{l}\text { cross- } \\
\text { linked } \\
\text { PEI }^{a}\end{array}$ & amines & 65 & 9.0 \\
\hline
\end{tabular}

${ }^{a_{\text {The }}}$ base PEI resins contain primary, secondary, and tertiary amines.

(BPE-1 and BPE-2). Table 1 shows that the TAC of the BPEI-1 and BPEI-2 resins are both equal to $9.0 \mathrm{mMol} / \mathrm{g}$. However, consistent with the reaction schemes of Figure 1, the TAC of the BSR-2 resin $(7.21 \mathrm{mMol} / \mathrm{g})$ is lower than that of the BSR-1 resin $(8.02 \mathrm{mMol} / \mathrm{g})$. Figure 2 shows the FT-IR spectra of the

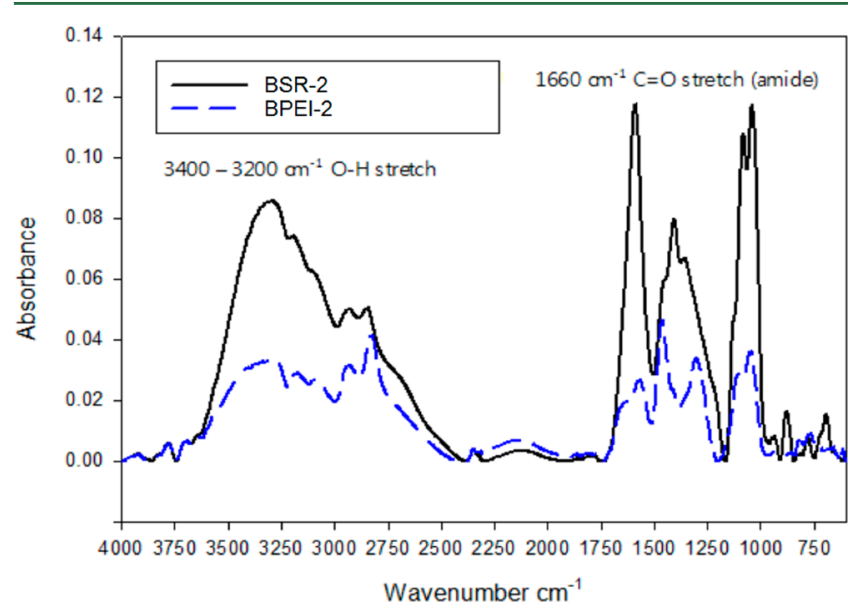

Figure 2. FT-IR spectra of BSR-2 and BPEI-2 resins. The SI provides a detailed description of the resin synthesis procedures.

BSR-2 and BPEI-2 resins. The FT-IR spectrum of the BSR-2 resin (Figure 2) exhibits some characteristic features of compounds with amide groups (e.g., $\mathrm{C}=\mathrm{O}$ stretch at 1660 $\mathrm{cm}^{-1}$ ) and hydroxyl groups (e.g., OH stretching at $3257 \mathrm{~cm}^{-1}$ ). Figure $1 \mathrm{~S}$ of the SI shows representative SEM micrographs of the BSR-1 and BSR-2 resin beads. Using the ImageJ software, ${ }^{13}$ we estimate the average diameter of the BSR-1 resin beads to be equal to $60.4 \mu \mathrm{m} \pm 11$. Note that the average diameter of the BSR-1 resin beads is significantly lower than those of STYDVB resin beads. The particle size distributions (PSD) of such commercial resin beads range from 300 to $1200 \mu \mathrm{m}$ with a mean diameter of $700 \mu \mathrm{m} .{ }^{15}$ Figure $2 S$ of the SI shows the PSD of the BSR-2 resin beads is comparable with that of commercial
STY-DVB resin beads. In this case, the PSD of the BSR-2 beads, which was measured using a Malvern Hydro $2000 \mathrm{~S}$ particle size analyzer, range from 352 to $829 \mu \mathrm{m}$ with a volumeaveraged mean diameter of $551 \mu \mathrm{m}$.

Batch Sorption and Regeneration Studies. Figure 3A shows the sorption isotherms of boron onto the BSR-1, BSR-2,
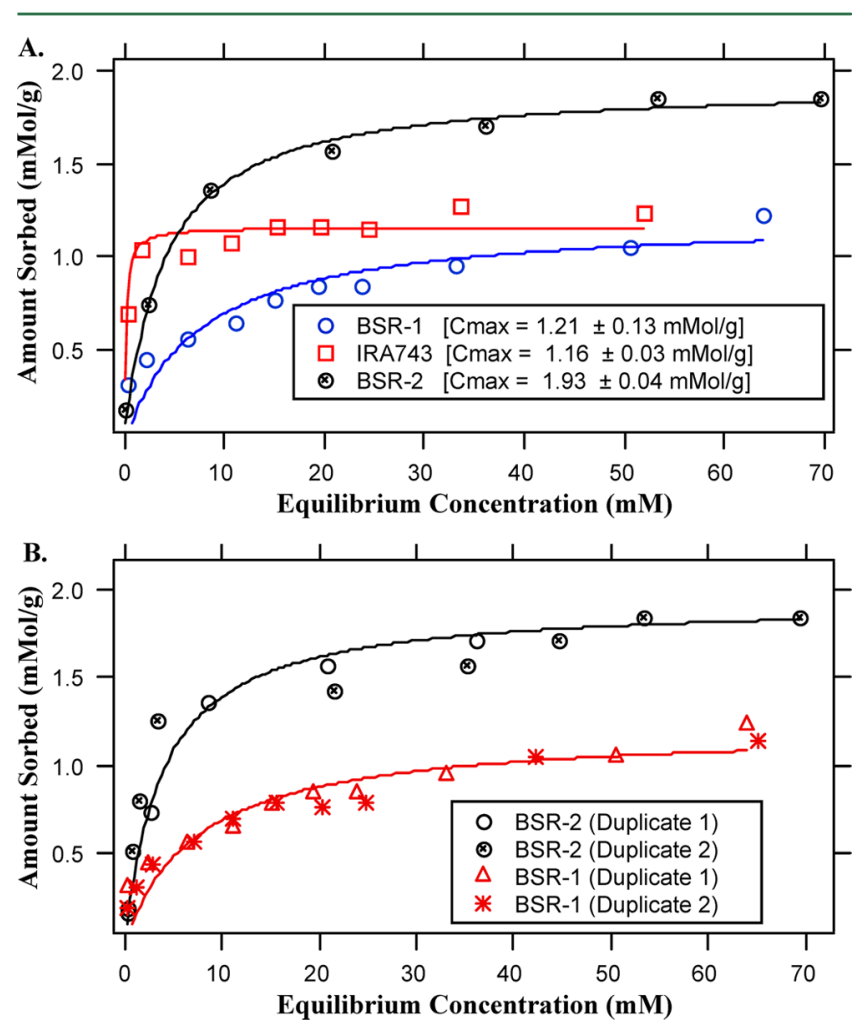

Figure 3. Boron sorption onto BSR-1, BSR-2, and Amberlite IRA-743 resins in deionized water at room temperature.

and Amberlite IRA 743 resins in DI water. Figure 3B highlights the reproducibility of the sorption measurements. We subsequently used the IGOR Pro $6^{20}$ software to fit each sorption isotherm to a Langmuir model as given below:

$$
Q_{\text {sorbed }}=\frac{K_{\mathrm{b}} C_{\mathrm{max}} C_{\mathrm{eq}}}{1.0+K_{\mathrm{b}} C_{\mathrm{eq}}}
$$

where $Q_{\text {sorbed }}(\mathrm{mMol} / \mathrm{g})$ is the mass of sorbed boron, $C_{\max }$ $(\mathrm{mMol} / \mathrm{g})$ is the resin sorption capacity at saturation, $K_{\mathrm{b}}$ $\left(\mathrm{mM}^{-1}\right)$ is the resin sorption constant, and $C_{\mathrm{eq}}(\mathrm{mM})$ is the equilibrium concentration of boron in the aqueous phase. Table 2 lists the estimated $C_{\max }$ and $K_{\mathrm{b}}$ values for the BSR-1, BSR-2, and Amberlite IRA-743 resins. Table 2 shows that the boron sorption capacity of the BSR-1 resin in DI water $\left(C_{\max }=1.21 \pm\right.$ $0.13 \mathrm{mMol} / \mathrm{g}$ ) is comparable to that of the STY-DVB Amberlite IRA-743 resin, which has a sorption $C_{\max }=1.16 \pm$ $0.03 \mathrm{mMol} / \mathrm{g}$. Note that our estimated $C_{\max }$ value for the Amberlite IRA-743 resin is very close to the measured value of $1.09 \mathrm{mMol} / \mathrm{g}$ reported by Xiao et al. ${ }^{12}$ Table 2 shows that the BSR-2 resin has a boron sorption capacity of $1.93 \pm 0.04$ $\mathrm{mMol} / \mathrm{g}$ in aqueous solution with equilibrium boron concentration of $\sim 70 \mathrm{mM}$. This sorption capacity is $66 \%$ percent larger than that of the Amberlite IRA-743 resin. Note that Figure 3A suggests the Amberlite IRA-743 resin has a higher sorption capacity at lower boron concentration, i. e. $\sim 2$ $\mathrm{mM}$. However, due to the limited sensitivity of our boron 
Table 2. Estimated Sorption Capacities $\left(C_{\text {max }}\right)$ and Sorption Constants $\left(K_{\mathrm{b}}\right)$ for BSR-1, BSR-2 and Amberlite IRA-743 Resins in Deionized Water and Model Electrolytes ${ }^{a}$

\begin{tabular}{|c|c|c|}
\hline resin & $C_{\max }(\mathrm{mMol} / \mathrm{g})$ & $K_{\mathrm{b}}\left(\mathrm{mM}^{-1}\right)$ \\
\hline BSR-1 (deionized water) & $1.21 \pm 0.13$ & $0.13 \pm 0.05$ \\
\hline BSR-1 (0.1 M NaCl) & $1.17 \pm 0.08$ & $0.32 \pm 0.11$ \\
\hline BSR-2 (deionized water) & $1.93 \pm 0.04$ & $0.26 \pm 0.03$ \\
\hline BSR-2 (SWRO permeate) ${ }^{b}$ & $2.13 \pm 0.10$ & $0.20 \pm 0.03$ \\
\hline IRA-743 (deionized water) & $1.16 \pm 0.03$ & $6.60 \pm 2.03$ \\
\hline
\end{tabular}

${ }^{a} C_{\max }$ and $K_{\mathrm{b}}$ values were determined by fitting each sorption isotherm to a Langmuir model. ${ }^{b}$ The composition of the seawater reverse osmosis (SWRO) model permeate is listed in Table $1 S$ of the SI.

detection method by titration (Figure $3 \mathrm{~S}$ of the SI), additional studies using more sensitive boron assays are needed to quantify the performance of the BSRs in aqueous solutions containing boron concentrations lower than $2 \mathrm{mM}$.

As a preliminary assessment of the selectivity of the BSR-1 and BSR-2 resins, we measured their boron sorption isotherms in (i) a $0.1 \mathrm{M} \mathrm{NaCl}$ solution and (ii) a simulated permeate of a SWRO desalination plant. Table $1 S$ of the SI lists the composition of the SWRO permeate, which was generated using the software IMSDesign. ${ }^{21}$ Figure 4 shows a small but

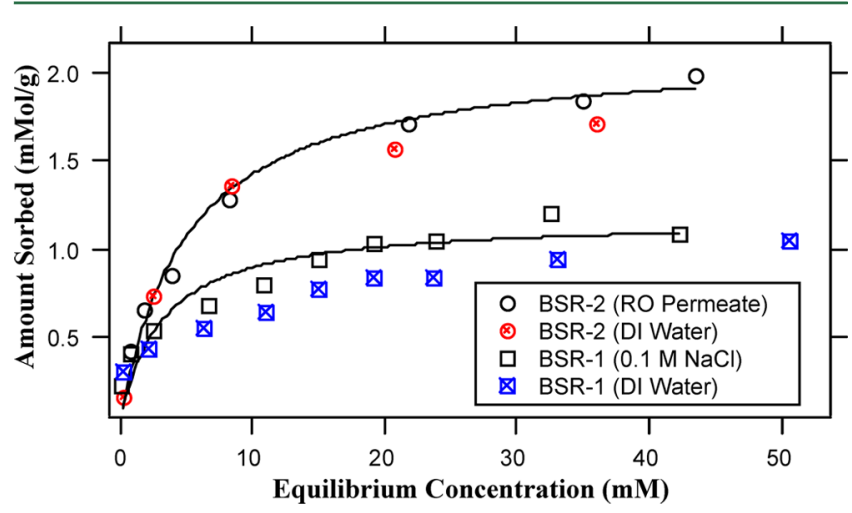

Figure 4. Boron sorption onto BSR-1 and BSR-2 resins in $0.1 \mathrm{M} \mathrm{NaCl}$ and model seawater reverse osmosis (SWRO) permeate at room temperature. The composition of the SWRO model permeate is listed in Table $1 \mathrm{~S}$ of the SI.

consistent increase of boron uptake for the BSR-1 resin in the $0.1 \mathrm{M} \mathrm{NaCl}$ solution compared to that in DI water. For the BSR-2 resin, however, this increase is negligible. In this case, the $C_{\max }$ value of the BSR-2 resin in the simulated SWRO permeate is very close to that in DI water (Figure 4 and Table 2 ). We speculate that the increase in boron uptake by the BSR1 resin in $0.1 \mathrm{M} \mathrm{NaCl}$ is the result of two synergistic effects: (i) an increase in borate $\left[\mathrm{B}(\mathrm{OH})_{4}{ }^{-}\right]$concentration with increasing solution ion strength (Figure $4 \mathrm{~S}$ of SI) and (ii) borate binding to the protonated tertiary amine groups of the resin via ion pairing. ${ }^{22}$ However, additional experiments are needed to validate this hypothesis. We also evaluated the regeneration potential of the BSR-1 and BSR-2 resins by measuring their boron sorption capacity in DI water after eluting the boronladen resins with a $1.0 \mathrm{~N} \mathrm{HCl}$ solution followed by a rinse with DI water and a wash with $0.1 \mathrm{~N} \mathrm{NaOH}$. Similar regeneration conditions were employed in previous studies of the Amberlite IRA-743 resin. ${ }^{9,10,12}$ We found that the boron sorption capacities of the pristine BSR-1 and BSR-2 resins in DI water were not affected by regeneration (Figure 5 and Table 3 ).

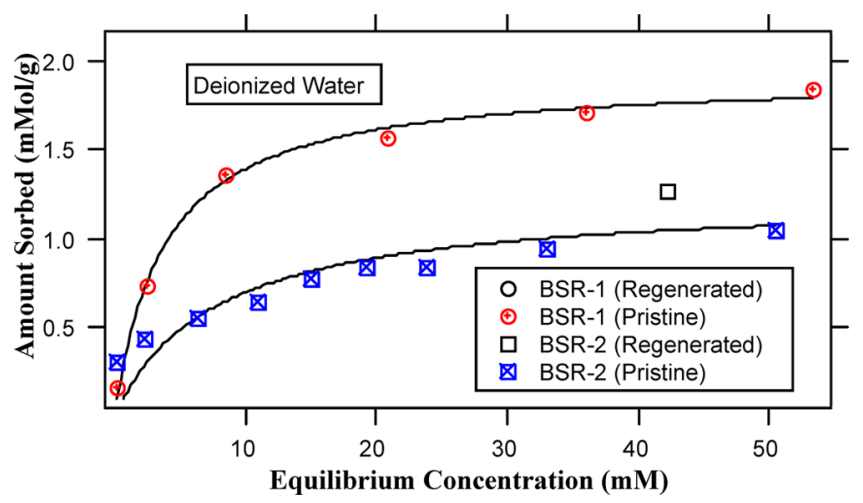

Figure 5. Boron sorption onto regenerated BSR-1 and BSR-2 resins in deionized water at room temperature. The saturated BSR-1 and BSR-2 resins were regenerated by elution with a $1.0 \mathrm{~N} \mathrm{HCl}$ solution followed by neutralization with $0.1 \mathrm{~N} \mathrm{NaOH}$ solution.

Table 3. Estimated Sorption Capacities $\left(C_{\max }\right)$ and Sorption Constants $\left(K_{\mathrm{b}}\right)$ for Pristine and Regenerated BSR-1 and BSR-2 Resins in Deionized Water ${ }^{a}$

\begin{tabular}{lcc}
\multicolumn{1}{c}{ resin } & $C_{\max }(\mathrm{mMol} / \mathrm{g})$ & $K_{\mathrm{b}}\left(\mathrm{mM}^{-1}\right)$ \\
BSR-1 (pristine) & $1.21 \pm 0.13$ & $0.13 \pm 0.05$ \\
BSR-1 (regenerated) ${ }^{b}$ & $1.23 \pm 0.16$ & $0.13 \pm 0.06$ \\
BSR-2 (pristine) & $1.93 \pm 0.04$ & $0.26 \pm 0.03$ \\
BSR-2 (regenerated) $^{b}$ & $1.92 \pm 0.05$ & $0.26 \pm 0.04$
\end{tabular}

${ }^{a} C_{\max }$ and $K_{\mathrm{b}}$ values were determined by fitting each sorption isotherm to a Langmuir model ${ }^{b}$ The resins were regenerated using a standard acid wash with a $1.0 \mathrm{M} \mathrm{HCl}$ solution followed by neutralization with a $0.1 \mathrm{NaOH}$ solution.

The overall results of the sorption experiments suggest that branched PEI beads provide versatile building blocks for the preparation of boron-chelating resins. As shown in Table 1, the base PEI beads have a high content of $\mathrm{N}$ groups $(9.0 \mathrm{mMol} / \mathrm{g})$ including reactive primary and secondary amine groups. Thus, they can be functionalized with compounds such as polyols and lactones to afford resins with high densities of boron-chelating groups. ${ }^{7,17,18}$ Based on the mechanisms of boron coordination with vicinal diol groups proposed by Yoshimura et al., ${ }^{23}$ we postulate the formation of two types of complexes in our boron-selective PEI resins. For the BSR-1 resin, we hypothesize that the mechanism of boron coordination involves the formation of a tetradentate and bischelate complex of boron/ borate with two hydroxyl groups from two different and contiguous branches of the resin (Figure 6). For the BSR-2 resin, we postulate a mechanism of boron coordination involving the formation of a tetradentate and monochelate complex of boron/borate with four hydroxyl groups from the same branch of a resin bead (Figure 6). Note that in both coordination models, the tertiary amines of the BSR-1 and BSR-2 resins are not coordinated to boron (Figure 6). We postulate that these tertiary amine groups provide buffering capacity inside the BSR-1 and BSR-2 resins for favorable boron sorption at lower $\mathrm{pH}$ by binding the protons released by boric acid following complexation by the resin diol groups. ${ }^{23}$ We also speculate that the protonated tertiary amines of the BSR-1 and BSR-2 resins could bind additional boron via ion-pairing with borate ions. Finally, we would like to mention that these hypothetical models of boron/borate coordination with the hydroxyl groups of the BSR-1 and BSR-2 resins (Figure 6) have 

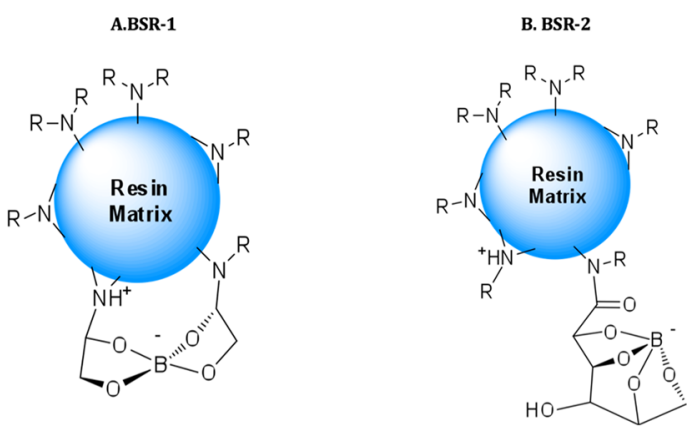

Figure 6. Postulated mechanisms of boron coordination with the BSR1 and BSR-2 PEI resins in aqueous solutions. These coordination models have not been validated by independent spectroscopic and atomistic simulation studies.

not been validated by independent spectroscopic and atomistic simulation studies.

Environmental Implications. As previously stated in the Introduction, extraction of boron from solutions is important in various environmental/industrial processes including (i) desalination, (ii) ultrapure water treatment, and (iii) nuclear power generation. ${ }^{1-4}$ In SWRO desalination plants, several strategies have been evaluated to extract boron from aqueous solutions water including (i) the addition of $1-2$ additional RO passes with high $\mathrm{pH}(\sim 9)$ adjustment ${ }^{24,25}$ and (ii) the utilization of enhanced membrane processes such as micellar enhanced ultrafiltration. ${ }^{24}$ However, due to its ease of implementation, sorption with selective and regenerable resins has emerged as an efficient process extracting boron from aqueous solutions. ${ }^{2}$ The overall results of our experiments suggest that cross-linked branched polyethylenimine (PEI) beads provide versatile and promising building blocks for the preparation of boron-selective resins with high sorption capacity. Additional investigations are being conducted in our laboratory to optimize the physical properties (e.g., particle size distribution and mechanical strength) and performance (e.g., sorption capacity and regeneration efficiency) of our PEI-based family of boron-chelating resins in environmentally relevant conditions including electrolyte solutions containing low concentrations of boron $(<2 \mathrm{mM})$.

\section{ASSOCIATED CONTENT}

\section{S Supporting Information}

Detailed description of methods and procedures used to synthesize the new resins, and supporting tables and figures. This material is available free of charge via the Internet at http://pubs.acs.org.

\section{AUTHOR INFORMATION}

\section{Corresponding Author}

*E-mail: mdiallo@kaist.ac.kr; Diallo@wag.caltech.edu; phone: 626-395-8133.

\section{Notes}

The authors declare the following competing financial interest(s): Prof. Mamadou S. Diallo is the co-founder of a start-up company (AquaNano) that is scaling and commercializing a new generation of high performance media based on branched macromolecules.

\section{ACKNOWLEDGMENTS}

This research was carried out at the California Institute of Technology and AquaNano, LLC. Selected materials characterization studies (FT-IR and SEM) were carried out at the Korea Advanced Institute of Science and Technology (KAIST). Funding for this research was provided by the U.S National Science Foundation (NSF) (CBET Award 0506951). M.S.D. and D.P.C. were supported by the KAIST EEWS Initiative (NT080607C0209721). W.A.G. III was supported partially by the KAIST World Class University (WCU) program (NRF-312008-000-10055).

\section{REFERENCES}

(1) Elimelech, M.; Phillip, W. A. The Future of seawater desalination: energy, technology, and the environment. Science 2011, 333, 712-717.

(2) Xu, Y.; Jiang, J. Q. Technologies for boron removal. Ind. Eng. Chem. Res. 2008, 47, 16-24.

(3) Grinstead, R. R. Removal of boron and calcium from magnesium chloride brines by solvent-extraction. Ind. Eng. Chem. Prod. Res. Dev.. 1972, 11, 454-460.

(4) Ocken, H. An Evaluation Report of Enriched Boric Acid in European PWRs; EPRI Report 1003124; Electric Power Research Institute, 2001.

(5) Blevins, D. G.; Lukaszewski, K. M. Boron in plant structure and function. Annu. Rev. Plant. Phys. 1998, 49, 481-500.

(6) Campbell, S. A. The Science and Engineering of Microelectronic Fabrication, 2nd ed.; Oxford University Press: New York, 2001.

(7) Smith, B. F.; Robison, T. W.; Carlson, B. J.; Labouriau, A.; Khalsa, G. R. K.; Schroeder, N. C.; Jarvinen, G. D.; Lubeck, C. R.; Folkert, S. L.; Aguino, D. I. Boric acid recovery using polymer filtration: studies with alkyl monool, diol, and triol containing polyethylenimines. J. Appl. Polym. Sci. 2005, 97, 1590-1604.

(8) Vogel, A. I.; Svehla, G. Quantitative Inorganic Analysis; Longman, 1987.

(9) Simonnot, M. O.; Castel, C.; Nicolai, M.; Rosin, C.; Sardin, M.; Jauffret, $\mathrm{H}$. Boron removal from drinking water with a boron selective resin: Is the treatment really selective? Water Res. 2000, 34, 109-116.

(10) Kaftan, O.; Acikel, M.; Eroglu, A. E.; Shahwan, T.; Artok, L.; Ni, C. Y. Synthesis, characterization and application of a novel sorbent, glucamine-modified MCM-41, for the removal/preconcentration of boron from waters. Anal. Chim. Acta 2005, 547, 31-41.

(11) Gazi, M.; Galli, G.; Bicak, N. The rapid boron uptake by multihydroxyl functional hairy polymers. Sep. Purif. Technol. 2008, 62, 484488.

(12) Xiao, Y. K.; Liao, B. Y.; Liu, W. G.; Xiao, Y.; Swihart, G. H. Ion exchange extraction of boron from aqueous fluids by Amberlite IRA 743 resin. Chin. J. Chem. 2003, 21, 1073-1079.

(13) Rasband, W. S. Image); U. S. National Institutes of Health: Bethesda, MD. Available online at http://imagej.nih.gov/ij/.

(14) ASTM D2187-9 Standard Test Methods for Physical and Chemical Properties of Particulate Ion-Exchange Resins. Available online at http:// www.astm.org/Standards/D2187.htm.

(15) Harland, C. E. Ion-Exchange: Theory and Practice, 2nd ed.; Royal Society of Chemistry: London, 1994.

(16) Sherrington, D. C. Preparation, structure and morphology of polymer supports. Chem. Commun. 1998, 2275-2286.

(17) Frechet, J. M. J.; Boz, E.; Chi, Y.; Diallo, M. S. Extraction of Anions from Solutions and Mixtures Using Hyperbranched Macromolecules. U.S. Patent Application 2010/0181257 A1, July 22, 2010.

(18) Diallo, M. S.; Yu, C. J. Soluble Anion Exchangers from Hyperbranched Macromolecules. U.S. Patent Application 2011/ 0315636 Al, December 29, 2011.

(19) Chang, H. T.; Charmot, D. Zard, S. P. Polyamine Polymers. US Patent 7,342,083 B2, 2008.

(20) WaveMetrics. IGOR Pro 6. Available online at http://www. wavemetrics.com/.

(21) Hydranautics. IMSDesign. Available online at http://www. membranes.com/index.php?pagename=imsdesign. 
(22) Hershey, J. P.; Fernandez, M.; Milne, P. J.; Millero, F. J. The ionization of boric acid in $\mathrm{NaCl}, \mathrm{Na}-\mathrm{Ca}-\mathrm{Cl}$ and $\mathrm{Na}-\mathrm{Mg}-\mathrm{Cl}$ solutions at $25{ }^{\circ} \mathrm{C}$. Geochim. Cosmochim. Acta 1986, 50, 143-148.

(23) Yoshimura, K.; Miyazaki, Y.; Ota, F.; Matsuoka, S.; Sakashita, H. Complexation of boric acid with the N-methyl-D-glucamine group in solution and in crosslinked polymer. J. Chem. Soc. Faraday. Trans. 1998, 94, 683-689.

(24) Busch, M. Boron removal in sea water desalination. Available online at http://www.idswater.com/Common/Paper/Paper_58/ Paper MarkusBusch.pdf.

(25) Roh, J.; Bartels, C.; Wilf, M. Use of Dendrimers to Enhance Selective Separation of Nanofiltration and Reverse Osmosis Membranes; Desalination and Water Purification Research and Development Report No. 140; 2009. Available online at http: www.usbr.gov/ pmts/water/publications/reportpdfs/report140.pdf. 